\title{
Effect of periampullary diverticulum on technical success and complications of endoscopic retrograde cholangiopancreatography: Single center experience
}

\author{
Mohammed A. Omar
}

\author{
Department of General Surgery, Faculty of Medicine, Sohag University, 82511 Sohag, Egypt
}

\section{Abstract}

Key words

Context: The incidence of the periampullary duodenal diverticulum (PAD) varies widely from 1 to $32.8 \%$. Although it is usually asymptomatic, its association with various pathological conditions such as choledocholithiasis increased the incidence of complications and cannulation failures after endoscopic retrograde cholangiopancreatography (ERCP) has been well recognized in various studies. Aim: The aim of this study was to investigate and compare the success rate, difficult cannulation, and complications between patients with and without PAD. Settings and Design: A prospective observational study. Subjects and Methods: The study includes 1022 consecutive patients who underwent an ERCP during the period from June 2010 to June 2015. The patients were divided into 2 groups according to the presence (Group A, 114 patients) or absence (Group B, 908 patients) of PAD. Statistical Analysis Used: SPSS version 16. Results: Successful cannulation was achieved in up to $90.4 \%$ and $95.9 \%$ in Groups A and $\mathrm{B}$, respectively $(P=0.12)$. The difficulty at attempting this goal was different between the groups $(33.3 \%$ vs. $16 \%, P<0.001)$. Duodenal perforation and recurrent biliary stones formation were the only significant post-ERCP complications between both groups. Multivariate logistic regression analysis showed 3 significant variables (abnormal papilla, the presence of diverticula, and stricture) with odds ratios indicating a difficult cannulation attempt. Conclusion: The finding of a PAD should not be considered an obstacle to a successful biliary cannulation, but requires more skills. However, it is associated with difficult cannulation, prolonged cannulation and procedure time, decreased the rate of successful stone removal, and increased the incidence of primary and recurrent biliary stones formation.

Complications, endoscopic retrograde cholangiopancreatography, periampullary diverticulum
\end{abstract}

\section{Introduction}

Periampullary duodenal diverticulum (PAD) was initially described by a French pathologist, Chomel, in 1710, ${ }^{[1]}$ first well-documented report was made by Morgagni in

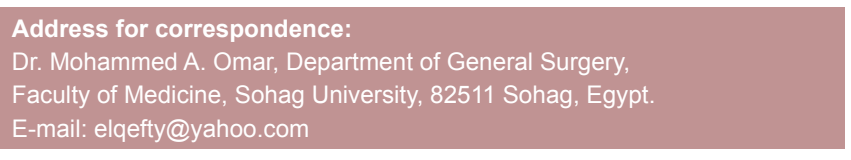

\begin{tabular}{|l|c|}
\hline \multicolumn{2}{|c|}{ Access this article online } \\
\hline \multirow{2}{*}{$\begin{array}{l}\text { Website: } \\
\text { www.jdeonline.in }\end{array}$} & Quick Response Code \\
\hline DOI: & \\
10.4103/0976-5042.173960 & \\
\hline
\end{tabular}

$1762^{[2]}$ and it was regarded an anatomic curiosity until 1913 when the radiological demonstration was done by Case. ${ }^{[3]}$ Duodenal diverticula are pouches of the mucosa, submucosa, and scattered muscle cells that extend through the intestinal wall. ${ }^{[4]}$ It is a common finding, and the pathophysiological mechanism of occurrence may include both traction and pulsion. ${ }^{[5]}$ They are commonly situated on the medial aspect of the second part of the duodenum

This is an open access article distributed under the terms of the Creative Commons Attribution-NonCommercial-ShareAlike 3.0 License, which allows others to remix, tweak, and build upon the work non-commercially, as long as the author is credited and the new creations are licensed under the identical terms.

For reprints contact: reprints@medknow.com

How to cite this article: Omar MA. Effect of periampullary diverticulum on technical success and complications of endoscopic retrograde cholangiopancreatography: Single center experience. J Dig Endosc 2015;6:149-57. 
and are usually within $2-3 \mathrm{~cm}$ of the ampulla of Vater. ${ }^{[6]}$ Such lesions are believed to be primarily acquired during the later decades of life, with the peak incidence occurring in individuals between 50 and 60 years of age ${ }^{[6]}$ with a slight female preponderance. ${ }^{[7]}$ The incidence of PAD widely varies from 1 to $32.8 \%$ based on different diagnostic approaches. ${ }^{[5,7-10]}$ Although PAD is usually asymptomatic, its association with various pathological conditions such as choledocholithiasis increased the incidence of complications and cannulation failures after endoscopic retrograde cholangiopancreatography (ERCP) has been well recognized in various studies. ${ }^{[7,10-12]}$

The conundrum still exists, because many of the published studies confer conflicting results regarding the true impact of PAD on technical success and complications of an ERCP. More studies should be performed with the aim to determine the ERCP success rate and its related complications in patients with PAD ${ }^{[13]}$ Therefore, the aim of this study was to investigate and compare the success rate, difficulty at cannulation, and complications between patients with and without PAD at our center of ERCP experience.

\section{Subjects and Methods}

\section{Study design}

This was a prospective observational study. The study includes 1116 consecutive patients who underwent an ERCP during the period from June 2010 to June 2015. The research proposal was conducted after approval of the Research and Ethics Committee of our hospital.

\section{Patients}

Patients undergoing ERCP were eligible for enrollment in the study. Exclusion criteria were: Age $<18$ years, pregnancy or breastfeeding, previous endoscopic sphincterotomy (ES) or placement of endoprostheses, upper gastrointestinal obstruction, patients with surgically altered anatomy (Billroth II or Roux-en-Y anastomosis), acute illness such as hypotension, hypoxia, and hemodynamic instability, acute myocardial infarction within 3 months before the procedure, and coagulopathy. As a result, 1022 patients were finally divided into 2 groups according to the presence (Group A as the case group, 114 patients) or absence of PAD (Group B as the control group, 908 patients).

Demographic characteristics, medical history, physical examination, American Society of Anesthesiology (ASA) scores, ${ }^{[14]}$ and imaging studies, as well as technical details and findings from the ERCP regarding those patients, were recorded in a database. Any complication taking place during or after the procedure was also entered into the records. Each patient or his/her relatives give a written informed consent after receiving verbal and written explanations about ERCP and possible postprocedure complications.

\section{Procedures}

All ERCP procedures were performed using the Pentax lateral view endoscope (ED-3440T and ED-3485T). Selective cannulation of the common bile duct (CBD) was done using a triple lumen papillotome and was aided in difficult cases by a slippery guidewire. In cases of failed cannulation, a metal tip cannula may be attempted. If cannulation failed a pre-cut papillotomy was done using the needle knife.

The following parameters were recorded: Presence and size of PAD, location of papilla in relation to PAD, time of deep $\mathrm{CBD}$ cannulation, $\mathrm{CBD}$ diameter, number and size of $\mathrm{CBD}$ stones, performed treatment, and the total procedure time.

\section{Definitions}

Bile duct diameter was the measured maximal duct diameter within $2 \mathrm{~cm}$ of the papilla adjusted for X-ray magnification. ${ }^{[15]}$ Cannulation time was measured between the time when the papillotome was advanced out of the endoscope and the time when successful deep cannulation was evidenced by injection of contrast. ${ }^{[15]}$ Total procedure time was recorded from the time the endoscope was positioned against the papilla until it was withdrawn. ${ }^{[15]}$ The size of stone was measured after correction for the magnification by using the known diameter of the duodenoscope on the same radiograph as a reference. ${ }^{[16]}$ Successful cannulation was defined as deep instrumentation of the biliary tree, and a cholangiogram was obtained. ${ }^{[17]}$ Cannulation attempt was defined as sustained contact between the cannulating device and the papilla for at least $5 \mathrm{~s}^{[17]}$ or as any obvious repositioning of the cannulation device into the papillary orifice. ${ }^{[18]}$ Difficult biliary cannulation was defined as failure of biliary access despite 10 min of attempted biliary cannulation, more than 5 attempts to enter the $\mathrm{CBD}$, more than five attempted unintentional pancreatic duct (PD) cannulations or the use of the pre-cut technique. ${ }^{[15]}$ The ampulla of Vater was characterized as abnormal when features of inflammation or bulging from an impacted stone or infiltrating adenoma were noticed. ${ }^{[7]} \mathrm{A}$ PAD was defined as a depressed lesion of $>5 \mathrm{~mm}$ with intact mucosa within a radius of $2.5 \mathrm{~cm}$ of the papilla. The size of PAD was arbitrarily classified as large $(>1.5 \mathrm{~cm})$ if a fully inflated biliary stone extraction balloon could be easily placed within the diverticular lumen, but if the balloon could not be positioned in the diverticulum, they were classified as small $(<1.5 \mathrm{~cm}) .{ }^{[5]}$ PAD were classified into 3 different types according to the position of the major duodenal papilla; type I: Papilla located inside the diverticulum, type II: Papilla located at the margin of the diverticulum, and type III: Papilla located outside the diverticulum (within $2.5 \mathrm{~cm}$ ). ${ }^{[9,10]}$ Patients with a papilla far away from the diverticulum were excluded. Complete CBD clearance was considered when all the stones were extracted, and no filling defects were seen at the final cholangiography or by sweeping the duct with an extraction balloon at the end. ${ }^{[7]}$ Post ERCP complications include at least one of these post ERCP pancreatitis, gastrointestinal perforation, and bleeding. ${ }^{[13]}$ Post ERCP pancreatitis was 
diagnosed when new-onset or increased abdominal pain lasted for more than $24 \mathrm{~h}$ and associated with an increase in serum amylase level of at least three times greater than the normal upper limit after the procedure. ${ }^{[19]}$ Bleeding was defined as the presence of melena, hematochezia, or hematemesis associated with a hemoglobin decrease of at least $2 \mathrm{~g} / \mathrm{dl}$ or the need for blood transfusion. ${ }^{[20]}$ Cholangitis was defined as the occurrence of fever, chills, elevated liver enzymes, and or positive blood culture within $48 \mathrm{~h}$ after the procedure. ${ }^{[20]}$ Perforation: A diagnosis of perforation required a radiographic finding of free or retroperitoneal air or extravasations of contrast material. ${ }^{[20]}$ Stent occlusion was based on presentation with jaundice, cholangitis, or cholestasis which necessitates an intervention. ${ }^{[21]}$ Recurrence biliary stones were defined as development of stones not earlier than 6 months after complete removal of previous bile duct stones. ${ }^{[22]}$ Early morbidity comprised all complications occurring during initial treatment or within 30 days of treatment. Late morbidity was defined as all complications occurring during follow-up (after 30 days).

\section{Follow-up and study outcomes}

After ERCP, all patients monitored in the ward by the endoscopist for early detection of post-ERCP complications for $24 \mathrm{~h}$. The patients were evaluated at the outpatient clinic on 10 and 30 days, 6 months and then yearly for at least 2 years, to assess the occurrence of late complications. The primary endpoint of the study was to investigate the influence of PAD on technical success and rate of complications in ERCP. The secondary endpoint was to investigate the effect of the type of PAD on successful and technique of cannulation.

\section{Statistical analysis}

Statistical analysis was made using the Statistical Package for Social Sciences (SPSS) version 16 (SPSS Inc., Chicago, IL, USA). Categorical variables were analyzed by the Chi-square test and Fisher's exact test, as appropriate, while continuous variables were expressed as mean \pm standard deviation and analyzed using Student's t-test. A binary logistic regression model was used for the prediction of difficulty at cannulation for the procedure. Odds ratios and 95\% CIs were reported for each factor entered in the regression equation. The level of statistical significance was set at $P<0.05$.

\section{Results}

The incidence of PAD was 114 of 1022 patients (11.2\%). There was no difference in male/female ratio (55/59 vs. $420 / 488$, $P=0.86$ ) between the two study groups, and the mean age of patients with PAD was significantly older (52 vs. 41.4 years, $P<0.001)$. Regarding medical history and indications for ERCP, there were no significant differences between both groups. A better general condition (ASA score I) was noted in patients without $\operatorname{PAD}(31.7 \%$ vs. $18.4 \%, P=0.04)$. With regard to laboratory parameters, levels of serum total and direct bilirubin as well as liver enzymes were significantly lower in patients with PAD. The initial abdominal ultrasonography (US) and magnetic resonance cholangiopancreatography (MRCP) revealed $\mathrm{CBD}$ stones more frequently in Group A $(79.8 \%$ vs. $69.4 \%, P=0.41)$ and more cases of CBD stricture in Group B $(27 \%$ vs. $15.8 \%$, $P=0.06)$ [Table 1].

The papilla was undetectable in 3 patients with $\operatorname{PAD}(2.6 \%)$ and in 11 patients without $\operatorname{PAD}(1.2 \%)(P=0.23)$. The papilla had abnormal appearance more often in Group B (13.5\% vs. 8.8\%, $P=0.1)$. Successful cannulation achieved in $90.4 \%(103 / 114)$ and $95.9 \%(871 / 908),(P=0.12)$ that was difficulty performed in $33.3 \%$ (38 patients) and $16 \%$ (145 patients) $(P=0.001)$, in Groups A and B, respectively.

There was statistically significant difference between the mean cannulation time $(16.2 \pm 7.3$ vs. $7.2 \pm 3.1 \mathrm{~min}$, $P=0.001)$, and the mean total procedure $(45 \pm 13.1$ vs. $32.2 \pm 3.2 \mathrm{~min}, P=0.02$ ) between both groups. The proportion of standard sphincterotomy $(88.3 \%$ vs. $86.1 \%$, $P=0.76)$, pre-cut papillotomy $(11.7 \%$ vs. $13.9 \%, P=0.89)$, PD cannulation $(21.2 \%$ vs. $20.4, P=0.69)$, and PD injection ( $7 \%$ vs. $8 \%, P=0.12$ ) were similar in both groups. There was no significant difference in cholangiographic finding between both groups, although the incidence of CBD stones was higher in the Group A (82.5\% vs. 70.4\%), and the incidence of stricture was higher in the Group B (26.3\% vs. $13.6 \%)$. There was significant difference in the CBD diameter $(12.1 \pm 2.3$ vs. $9.3 \pm 1.6, P=0.01)$ between both groups. Furthermore, there was significant difference between numbers $(2.1 \pm 0.8$ vs. $1.4 \pm 0.5, P=0.001)$ and size $(8.4 \pm 1.9$ vs. $6.9 \pm 1.6, P=0.01)$ of CBD stone (s) between patients with choledocholithiasis in both groups [Table 2].

According to the location of the papilla, type I PAD was found in 16 patients (14\%), type II was found in 65 patients $(57 \%)$ and type III was found in 33 patients (29\%). The size of the PAD was small in 64 patients $(56.1 \%)$, and was large in 50 patients $(43.9 \%)$. Successful cannulation was highly

\begin{tabular}{lccc}
\hline \multicolumn{4}{l}{ Table 1: Patient's baseline characteristics } \\
\hline Patients characteristics & $\begin{array}{c}\text { Patients } \\
\text { with PAD }\end{array}$ & $\begin{array}{c}\text { Patients } \\
\text { without PAD }\end{array}$ & $P$ \\
\hline Patients, $n(\%)$ & $114(11.2)$ & $908(88.8)$ & \\
Male/female & $55 / 59$ & $420 / 488$ & 0.86 \\
Age, years & & & \\
Mean \pm SD & $52 \pm 8.1$ & $41.4 \pm 9.5$ & $<0.001$ \\
Median (range) & $53(29-77)$ & $40(18-58)$ & $<0.001$ \\
ASA score I, $n(\%)$ & $21(18.4)$ & $288(31.7)$ & 0.04 \\
US/MRCP report, $n(\%)$ & & & \\
Dilated ducts without stones & $2(1.8)$ & $18(2)$ & 0.95 \\
CBD stones & $91(79.8)$ & $630(69.4)$ & 0.41 \\
Benign stricture & $4(3.5)$ & $61(6.7)$ & 0.06 \\
Malignant stricture & $14(12.3)$ & $184(20.3)$ & 0.09 \\
Bile leak & $2(1.8)$ & $11(1.2)$ & 0.71 \\
Choledochocele & $1(0.8)$ & $4(0.4)$ & 0.4 \\
\hline ASA American Society of Anesthesiology $($ US=Utrasonography, MRCP=Magnetic
\end{tabular}

$\mathrm{ASA}=$ American Society of Anesthesiology, US=Ultrasonography, MRCP=Magnetic resonance cholangiopancreatography, $\mathrm{SD}=\mathrm{Standard}$ deviation, $\mathrm{CBD}=\mathrm{Common}$ bile duct, $\mathrm{PAD}=$ Periampullary duodenal diverticulum 
achievable in type II and III than type I (93.8\% and $97 \%$ vs. $56.3 \%, P=0.003)$. Type I was the difficult type in cannulation ( $80 \%$ vs. $34.4 \%$ and $28.1 \%, P=0.001)$. There was no statistically significant difference with the method of cannulation (sphincterotomy and pre-cut) between different types of PAD [Table 3].

The results of endoscopic treatment according to the finding of ERCP in the two groups are listed in Table 4. Complete clearance of the CBD was achieved more easily in Group B than in Group A $(92.9 \%$ vs. 82.4, $P=0.02$ ), and this difference remained with all techniques used (basket/balloon, mechanical lithotripsy). In 10 patients $(11 \%)$ of Group $A$ and 28 patients of Group B (4.4\%) with choledocholithiasis, plastic stent was placed because of inability to use mechanical lithotripsy due to the presence of very large CBD stone (s) or hugely dilated CBD in need for drainage $(P=0.001)$.

There was no significant difference in the overall early morbidity or mortality rate between the two groups $(12.3 \% \mathrm{vs}$. $7.9 \%$ and $0.9 \%$ vs. $0.2 \%$, respectively).

Post ERCP pancreatitis occurred in 9 patients $(7.9 \%)$ in Group A and 45 patients (5\%) in Group B and was the most frequent complication $(P=0.6)$. All cases were managed conservatively, but only one case of the severe form of pancreatitis in Group B died in the intensive care unit. Bleeding occurred in one patient $(0.9 \%)$ in Group A, versus 10 patients $(1.1 \%)$ in Group B $(P=0.89)$. All cases were successfully treated with blood transfusion and endoscopic techniques for achieving hemostasis. Cholangitis occurred in one patient $(0.9 \%)$ in Group A (incomplete drainage), versus 8 patients $(0.9 \%)$ in Group B $(P=1)$ (6 after incomplete drainage, one after placement of a metal expandable stent despite adequate drainage, and one after unknown cause). Retroperitoneal perforation was the only significant difference between both groups, it occurred in 2 patients (1.8\%) in Group A, versus 1 patient $(0.1 \%)$ in Group B $(P=0.02)$, which were discovered immediately and managed conservatively. Cardiopulmonary complications occurred in one patient $(0.9 \%)$ in Group A (bradyarrthymia), versus 2 patients $(0.2 \%)$ in Group B (bradyarrthymia and pulmonary embolism) $(P=0.23)$. Cholecystitis occurred in 2 case $(0.2 \%)$, and basket trapping occurred in 1 case $(0.1 \%)$ only in Group B [Table 5].

The ERCP-related mortality rate was $0.9 \%$ vs. $0.2 \%$; one death was due to sever acute pancreatitis (Group B), one due to pulmonary embolism (Group A), and the last due to bradyarrhythmia arising during the procedure (Group B) [Table 5].

The median patient follow-up was 15.5 months, with a range of 0-36 months. There was a highly significant difference regarding recurrent biliary stone (s) formation between both groups $(4.9 \%$ vs. $0.6, P=0.001)$, while there was no significant
Table 2: Endoscopic retrograde cholangiopancreatography results after excluding patients with undetectable papilla and abandoned procedure

\begin{tabular}{|c|c|c|c|}
\hline ERCP results & $\begin{array}{l}\text { Patients } \\
\text { with PAD }\end{array}$ & $\begin{array}{c}\text { Patients } \\
\text { without PAD }\end{array}$ & $P$ \\
\hline Undetectable papilla & $3(2.6)$ & $11(1.2)$ & \\
\hline Abnormal papilla, $n(\%)$ & $10(8.8)$ & $123(13.5)$ & 0.1 \\
\hline Successful cannulation, $n(\%)$ & $103(90.4)$ & $871(95.9)$ & 0.12 \\
\hline Difficult cannulation, $n(\%)$ & $38(33.3)$ & $145(16)$ & 0.001 \\
\hline Cannulation time, mean $\pm S D$ & $16.2 \pm 7.3$ & $7.2 \pm 3.1$ & 0.001 \\
\hline Total procedure time, mean $\pm S D$ & $45 \pm 13.1$ & $32.2 \pm 3.2$ & 0.02 \\
\hline Standard sphincterotomy, $n(\%)$ & $91(88.3)$ & $750(86.1)$ & 0.76 \\
\hline Precut papillotomy, $n(\%)$ & $12(11.7)$ & $121(13.9)$ & 0.89 \\
\hline Patients with PD cannulation, $n(\%)$ & $23(21.2)$ & $185(20.4)$ & 0.69 \\
\hline Patients with PD injection, $n(\%)$ & $8(7)$ & $73(8)$ & 0.12 \\
\hline \multicolumn{4}{|l|}{ Cholangiography, $n(\%)$} \\
\hline Choledocholithiasis & $85(82.5)$ & $613(70.4)$ & 0.23 \\
\hline Stricture & $14(13.6)$ & $229(26.3)$ & 0.06 \\
\hline Dilated CBD without stones & $2(1.9)$ & $17(2)$ & 0.96 \\
\hline Bile leak & $1(1)$ & $8(0.9)$ & 0.86 \\
\hline Choledochocele & $1(1)$ & $4(0.4)$ & 0.3 \\
\hline CBD diameter, $n(\%)$ & $12.1 \pm 2.3$ & $9.3 \pm 1.6$ & 0.01 \\
\hline Number of CBD stone (s) & $2.1 \pm 0.8$ & $1.4 \pm 0.5$ & 0.001 \\
\hline Size of CBD stone (s) & $8.4 \pm 1.93$ & $6.9 \pm 1.6$ & 0.01 \\
\hline
\end{tabular}

Table 3: Endoscopic retrograde cholangiopancreatography findings according to periampullary duodenal diverticulum type

\begin{tabular}{lcccc}
\hline Variable & $\begin{array}{c}\text { Type I } \\
\boldsymbol{n}(\%)\end{array}$ & $\begin{array}{c}\text { Type II } \\
\boldsymbol{n}(\%)\end{array}$ & $\begin{array}{c}\text { Type III } \\
\boldsymbol{n}(\%)\end{array}$ & $\boldsymbol{P}$ \\
\hline Patients & $16(14)$ & $65(57)$ & $33(29)$ & \\
PAD size (\%) & & & & \\
$\quad$ Small & $3(18.8)$ & $39(60)$ & $22(66.7)$ & \\
$\quad$ Large & $13(81.2)$ & $26(40)$ & $11(33.3)$ & \\
Successful cannulation & $10(62.5)$ & $61(93.8)$ & $32(97)$ & 0.003 \\
Difficult cannulation & $8(80)$ & $21(34.4)$ & $9(28.1)$ & 0.001 \\
Standard sphincterotomy & $8(80)$ & $55(90.2)$ & $28(87.5)$ & 0.34 \\
Pre-cut & $2(20)$ & $6(9.8)$ & $4(12.5)$ & 0.45 \\
\hline
\end{tabular}

$\mathrm{PAD}=$ Periampullary duodenal diverticulum

Table 4: Endoscopic treatment after successful cannulation Endoscopic treatment $\quad$ Patients Patients $P$ with PAD without $n(\%) \quad$ PAD $n(\%)$

\begin{tabular}{llll}
\hline CBD stones & 85 (93.4) & $613(97.3)$ & 0.79
\end{tabular}

Complete clearance of CBD stones 75 (82.4) 585 (92.9) 0.02 CBD clearance by basket or balloon 61 (81.3) 555 (94.9) 0.01 CBD clearance by mechanical lithotripsy 14 (18.7) $30(5.1) \quad 0.001$ Stent placement in CBD stones $\quad 10(11) \quad 28(4.4) \quad 0.001$ ES and stent placement in strictures 14 (77.8) 229 (93.5) $\quad 0.48$ $\begin{array}{llll}\text { ES in dilated CBD without stones } & 2(100) & 17(94.4) & 0.87\end{array}$ $\begin{array}{llll}\text { ES and Stent placement in biliary leakage } \quad 1(50) & 8(72.7) & 0.07\end{array}$ ES and Stent placement in choledochocele $1(100) \quad 4(100) \quad 1$ ES=Endoscopic sphincterotomy, PAD=Periampullary duodenal diverticulum, $\mathrm{CBD}=$ Common bile duct

difference regarding stent occlusion $(12.5 \%$ vs. $19.1 \%, P=0.87)$ between patients with and without PAD [Table 5].

Jaurnal of Digestive Endoscopy Vol 6 | Issue 4 | October-December 2015 
To determine the independent predictors of technical difficulty at CBD cannulation, a multivariate logistic regression model was used. The variables found to be significant in univariate analyses were taken as candidate explanatory variables in a multivariate logistic regression analysis, to identify those risk factors associated with difficult cannulation in a multivariate setting, and to estimate their independent contributions adjusted for the effects of each of the other factors. Three variables (abnormal papilla, $\mathrm{PAD}$, and stricture) were identified to be independently associated with difficult cannulation. Periampullary diverticulum was the most risky factor for difficult cannulation (OR: 2.96). Type I raised the difficulty four-fold while type II raised the risk two- and half-fold, also large PAD was found as an independent significant risk factors for difficult cannulation (OR: 1.4) independently of the other related risk factors. Similarly, CBD stricture was found as an independent significant risk factors for difficult cannulation (OR: 1.3), and finally abnormal papilla was a barely significant risk factor for difficult cannulation (OR: 1.11) [Table 6].

\begin{tabular}{|c|c|c|c|}
\hline Variable & $\begin{array}{l}\text { Patients with } \\
\text { PAD } n(\%)\end{array}$ & $\begin{array}{c}\text { Patients without } \\
\text { PAD } n(\%)\end{array}$ & $P$ \\
\hline Pancreatitis & $9(7.9)$ & $45(5)$ & 0.6 \\
\hline Bleeding & $1(0.9)$ & $10(1.1)$ & 0.89 \\
\hline Cholangitis & $1(0.9)$ & $8(0.9)$ & 1 \\
\hline Perforation & $2(1.8)$ & $1(0.1)$ & 0.1 \\
\hline Cholecystitis & $0(0)$ & $2(0.2)$ & 0.2 \\
\hline Cardiopulmonary & $1(0.9)$ & $2(0.2)$ & 0.23 \\
\hline Basket impaction & $0(0)$ & $1(0.1)$ & 0.9 \\
\hline Total & $14(12.3)$ & 72 (7.9) & 0.31 \\
\hline Recurrent biliary stone ${ }^{*}$ & $5(4.9)$ & $5(0.6)$ & 0.001 \\
\hline Stent occlusion* & $4(12.5)$ & $54(19.1)$ & 0.87 \\
\hline Death & $1(0.9)$ & $2(0.2)$ & 0.54 \\
\hline
\end{tabular}

*Late complication. PAD=Periampullary duodenal diverticulum

\section{Discussion}

The second segment of duodenum is the common site for diverticular disease, with most lesions classified as periampullary diverticula. ${ }^{[23]}$ Such lesions are believed to be primarily acquired during the later decades of life, with the peak incidence occurring in individuals between 50 and 60 years of age ${ }^{[5]}$ with a slight female preponderance. ${ }^{[13]}$ This relationship with aging suggests that some form of a degenerative process involving the local supporting structures results in the development of PAD. ${ }^{[24]}$ However, such statistics were primarily culled from studies of patients with biliary stones or other biliary tract diseases and did not include healthy individuals. ${ }^{[2]]}$

The true prevalence of PAD in the general population is uncertain due to the diagnostic accuracy of various methods. Prevalence rates on radiographic studies are as high as 5-6\% while those at necroscopic investigations range from 5 to $19.4 \%{ }^{[25]}$ Prevalence rates from 4 to $9 \%$ to $25-32.8 \%$ have been reported at esophagogastroduodenoscopy, the average being from 10 to $20 \% .^{[5,7,10,11,13,16,23-27]}$ Our study showed the comparable result (11.2\%) with the average prevalence in the previous studies.

Most previous researches confirmed the relation between the high prevalence of PAD and the advanced age, ${ }^{[5,7,10,13,16,24-28]}$ and this relationship was also reconfirmed in our study since the mean age of patients was significantly higher in patients with PAD than others (52 vs. 41.4 years, $P<0.001$ ). In our study, the incidence of PAD was slightly higher in females ( $51.8 \%$ vs. $48.2 \%$ ) but not significant $(P=0.86)$, and this was comparable with most previous studies. ${ }^{[5,7,13,16,25,27,28]}$

Our results were comparable with the previous results regarding no significant difference in the medical history ${ }^{[13]}$ and indication ${ }^{[5,13,16]}$ for ERCP in patients with or without PAD.

\begin{tabular}{|c|c|c|c|c|}
\hline \multirow[t]{2}{*}{ Variable } & \multicolumn{2}{|c|}{ Univariate analysis } & \multicolumn{2}{|c|}{ Multivariate analysis } \\
\hline & OR $(95 \% \mathrm{Cl})$ & $P$ & OR $(95 \% \mathrm{Cl})$ & $P$ \\
\hline Age & $1.06(0.8-1.55)$ & 0.2 & $0.97(0.89-1.03)$ & 0.2 \\
\hline Females versus males & $0.64(0.15-2.78)$ & 0.55 & $0.81(0.63-1.23)$ & 0.4 \\
\hline Previous cholecystectomy & $0.79(0.42-1.50)$ & 0.47 & $0.67(0.99-1.002)$ & 0.09 \\
\hline ASA score I & $1.05(0.12-8.88)$ & 0.97 & $0.98(0.67-1.23)$ & 0.8 \\
\hline Total serum bilirubin & $0.89(0.52-1.41)$ & 0.1 & $0.92(0.65-1.23)$ & 0.56 \\
\hline Abnormal papilla & $1.24(1.11-2.37)$ & 0.01 & $1.19(1.03-1.78)$ & 0.04 \\
\hline \multicolumn{5}{|l|}{ PAD } \\
\hline PAD versus none & $3.51(2.98-7.87)$ & $<0.001$ & $2.96(1.78-4.56)$ & 0.03 \\
\hline Type I versus type III & $4.30(2.46-7.85)$ & $<0.0001$ & $3.9(1.16-7.42)$ & 0.001 \\
\hline Type II versus type III & $2.42(1.17-4.00)$ & 0.002 & $2.39(1.23-3.52)$ & 0.001 \\
\hline Large versus small & $1.61(1.17-3.85)$ & 0.02 & $1.5(1.22-1.96)$ & 0.01 \\
\hline Choledocholithiasis & $1.67(1.80-3.56)$ & 0.046 & $0.89(0.65-1.03)$ & 0.3 \\
\hline Stricture & $1.78(1.01-4.11)$ & 0.049 & $1.3(1.09-1.61)$ & 0.01 \\
\hline CBD diameter & $0.56(0.23-0.89)$ & 0.11 & $0.55(0.45-0.87)$ & 0.78 \\
\hline
\end{tabular}

$\overline{\mathrm{ASA}}=\mathrm{American}$ Society of Anesthesiology, $\mathrm{PAD}=$ Periampullary duodenal diverticulum, $\mathrm{CBD}=\mathrm{Common}$ bile duct, $\mathrm{Cl}=$ Confidence interval, $\mathrm{OR}=\mathrm{Odds}$ ratio 
On contrary, another study showed that obstructive jaundice was significantly more prevalent in patients without PAD. ${ }^{[7]}$ We reconfirm the previous studies ${ }^{[7,16]}$ regarding significant association between patients with PAD and a worse general condition $(P=0.04)$. This may be attributed to the significant old age of this group of patients. Our result agrees with Mohammed Alizadeh et al., ${ }^{[13]}$ regarding lower significant laboratory parameters, levels of serum total and direct bilirubin as well as liver enzymes in the group with PAD.

Panteris et al..$^{[7]}$ found a significantly higher prevalence of undetectable papilla in patients without diverticula. This was not confirmed in our study, since there was no significant difference between both groups $(2.6 \%$ vs. $1.2 \%, P=0.23)$, and these result was nearly comparable with Geraci et al., ${ }^{[25]}$ who showed none of the patients with diverticulum had undetectable papilla. The inability to detect the papillary orifice in Group A may be attributed to intradiverticular position of the papilla, whereas, in Group B, there was edema, structuring, or invasion of the duodenal wall by malignancy. In this study, there was no significant difference between abnormal papilla and the presence or absence of PAD (8.8\% vs. $13.5 \%$, $P=0.1)$. This was disagreeing with Panteris et al. ${ }^{[7]}$ who show a significant relation between abnormal papilla and patients without PAD.

There is conflicting evidence regarding the impact of PAD on the success of ERCP cannulation; some authors report an impact, ${ }^{[8,29,30]}$ others a lack of impact. ${ }^{[5,7,8,10]}$ Our study showed that successful cannulation rate was insignificant between both groups, although it was higher in patients without PAD (90.4\% vs. 95.9\%, $P=0.12)$, and this was consistent with many studies. ${ }^{[5,7,8,10,16,27,28]}$ On contrary, many studies showed that successful cannulation in patients with PAD was found to be significantly lower compared with patients without PAD ${ }^{[13,30-33]}$ These conflicting results might be partly due to differences in study design, patients, operator's experience and the use of new duodenoscopes, special accessories, techniques that facilitate CBD cannulation even in patients with a intradiverticular papilla or a floppy papilla on the edge of a diverticulum and definition of treatment success (e.g., if failure to cannulate during the initial ERCP session was considered treatment failure or if alternative cannulation attempts such as the precut technique were not used). ${ }^{[16,27]} \mathrm{On}$ contrary, other studies showed that the presence of diverticula may result in dysfunction of the sphincter of Oddi, which would reduce resistance against the sphincterotome, thereby enhancing cannulation success. ${ }^{[5,7,34]}$ It has been found by biliary manometry that the muscular tone and contractions of the sphincter are decreased in patients with PAD, and this has been attributed to the sustained mechanical compression of the lower CBD by a distended periampullary diverticulum, either as a result of food impaction or increased intraduodenal pressure. This condition can facilitate a more convenient attempt at cannulation because the sphincter can be less resistance to the insertion of a cannulation catheter. ${ }^{[35]}$
Likewise, difficulty at cannulation was addressed in many studies, in some of them; the results were significant toward a more difficult cannulation in patients with $\mathrm{PAD}^{[13,30,33]}$ and this was comparable with our results $(P=0.001)$, whereas no difference was found in others. ${ }^{[10,16,25]}$ On contrary, other studies found that the difficulty of attempting cannulation was significant toward a more difficult cannulation in patients without diverticula. ${ }^{[5,7]}$

There was statistically significant difference between the mean cannulation time $(16.2 \pm 7.3$ vs. $7.2 \pm 3.1 \mathrm{~min}, P=0.001)$, and the mean total procedure $(45 \pm 13.1$ vs. $32.2 \pm 3.2 \mathrm{~min}$, $P=0.02$ ) between both groups. This may be attributed to our significant difficult cannulation between both groups. On contrary, Panteris et al., ${ }^{[7]}$ found that the mean duration of the procedure was similar in both groups.

There was no statistically significant difference between standard sphincterotomy and pre-cut papillotomy between both groups. Similarly, Katsinelos et al., ${ }^{[16]}$ showed that no significant differences were observed in different techniques to achieve CBD cannulation between patients with and those without PAD. On contrary, two studies ${ }^{[5,7]}$ showed that pre-cut papillotomy was significant in patients without diverticula, while on study showed that ES was significant in patients with diverticula. ${ }^{[28]}$

Furthermore, there was no statistically significant difference between patients with $\mathrm{PD}$ cannulation and patients with $\mathrm{PD}$ injection between both groups. The previous results must be viewed only as a descriptive, because the cannulation and injection of the PD were not attempted in all patients and was not intended at all times.

There was no significant difference in the initial ulrasonography and MRCP and final ERCP finding between both groups. Our study was comparable with many studies showed that the incidence rate of a diverticulum in association with $\mathrm{CBD}$ stones is high but insignificant. ${ }^{[16,24,26,36-38]}$ On contrary, some other studies $^{[7,8,13,28,39]}$ showed a significant difference in the incidence rate of a diverticulum in association with CBD stones.

Formation of stone in the presence of PAD can be related to several probable hypotheses. First, it has been suggested that the dysfunction in the sphincter of Oddi, which in turn causes reflux of pancreatic fluid and intestinal content into the bile duct, bacterial infection of the bile duct, and formation of bile duct stone. ${ }^{[9,40]}$ It has been also argued that diverticula cause spasm of the sphincter and increase biliary tract pressure. This phenomenon may produce jaundice and cholangitis as well as predispose for CBD stones. ${ }^{[41]}$ Other showed that the accumulated food in the diverticulum, putting pressure on the end of the bile duct and sphincter of Oddi and leading to stricture of the sphincter. ${ }^{[42]}$ Furthermore, it has been hypothesized that PAD may cause functional biliary stasis possibly by compression of the distal part of the CBD 
that accounts for the increased incidence of pigment biliary stones. ${ }^{[43,44]}$ We agree with Mohammed Alizadeh et al. ${ }^{[13]}$ that although we were able to demonstrate an association between the presence of PAD and choledocholithiasis, pathological basis of this phenomenon is already undetermined and should be supported by further studies.

Our results also showed a significant association of $\mathrm{PAD}$ with $\mathrm{CBD}$ dilation, number of stones and larger $\mathrm{CBD}$ stones on cholangiogram. Our findings are consistent with those of other studies that enrolled patients for an ERCP as an indication for choledocholithiasis. ${ }^{[16,36,37,45,46]}$ In contrast, a similar study on patients undergoing ERCP for a wider range of indications showed that the presence of PAD was not associated with the higher incidence of larger stones or $\mathrm{CBD}$ dilation. ${ }^{[7]}$ Aslan et al., ${ }^{[27]}$ showed that there was no difference between the groups in terms of the number of CBD stones while average stone diameter was larger in patients with diverticula compared with those without diverticula.

The published data on the prevalence of PAD with respect to papilla are contradictory. Katsinelos et al., ${ }^{[16]}$ study revealed a higher rate of the papilla located at the rim of the diverticulum (Type II). A prospective study ${ }^{[7]}$ in a Greek cohort reported that PAD was most commonly located within $2 \mathrm{~cm}$ from the papilla (Type III). However, another two studies ${ }^{[9,10]}$ found that PAD was rarely located within $2 \mathrm{~cm}$ from the papilla. A recent study by Ozogul et al., showed that PAD type I was found in $41.3 \%$, type II was found in $41.7 \%$, and type III was found in $17 \%$ of patients. ${ }^{[47]}$ Our study revealed a higher rate of type II PAD (57\% vs. $14 \%$ and $29 \%$ ). The size of the PAD was smaller in 64 patients (56.1\%), and was larger in 50 patients (43.9\%). Aslan et al., ${ }^{[27]}$ showed that The size of the diverticulum was smaller than $2 \mathrm{~cm}$ in 90 patients $(83.3 \%)$, and $\geq 2 \mathrm{~cm}$ in 18 (16.7\%). The highest incidence of small diverticulum was type II (60\%) while the highest incidence of large diverticulum was type I (81.2\%). This result was agreeable with Boender et al., ${ }^{[29]}$ who concluded that the location of the papillary ostium may differ according to the size of the diverticulum.

Periampullary diverticula might affect cannulation success through anatomical damage to the location of the papillary ostium. ${ }^{[30,32,33]}$ Our results showed a highly achievable significant successful cannulation in type II and III in comparison to type I PAD (93.8\% and 97\% vs. 56.3\%, $P=0.003)$. Two studies showed that ${ }^{[32,33]}$ the location of the papilla in patients with failed cannulation was inside the diverticulum in $62 \%$ and $62.5 \%$ and outside the diverticulum in $22 \%$ and $25 \%$ respectively, whereas, in others ${ }^{[7,16,27]}$ no correlation can be established between the location of the papilla and cannulation success. We agree with Sherman et al., ${ }^{[4]}$ that a low cannulation rate in type I can be attributed to the inability of the endoscopist to detect the papilla.

Type I PAD (intradiverticular papilla) was the most difficult type of cannulation ( $80 \%$ vs. $34.4 \%$ and $28.1 \%, P=0.001)$, this result was comparable with a study showed that paradiverticular papilla (PAD types II or III) are usually easy to cannulate; ${ }^{[48]}$ however, when the papilla is located deep inside the diverticulum (PAD type I), the cannulation used to be difficult, and one has to use techniques that may help in this situation. ${ }^{[35]}$ On contrary, Panteris et al. ${ }^{[7]}$ showed that there was no statistical difference when judging the level of difficulty between different types of PAD.

ES was performed more frequently in type II and III (90.8\% and $87.9 \%)$, as compared with $80 \%$ in type $\mathrm{I}(P=0.34)$, while pre-cut was performed more frequently in type I (20\%), as compared with $9.2 \%$ and $11.4 \%$ in type II and III, respectively, but the difference did not reach statistical significance. Similarly, two studies ${ }^{[7,16]}$ showed that the classification of PAD into three types had no difference in different techniques to achieve CBD cannulation.

Complete clearance of CBD was less frequently achieved in the presence of diverticula ( 82.4 vs. $92.9 \%, P=0.02)$. Similarly, two studies ${ }^{[7,16]}$ showed that complete clearance of the CBD was achieved more easily in patients without diverticula than in patients with diverticula. This can be explained by the inability to perform complete sphincterotomies, especially when the papilla was inside the diverticulum, for fear of perforation and the presence of PAD limited the extension of sphincterotomy to allow complete clearance of stones. On contrary, many studies showed that complete clearance of stones from the $\mathrm{CBD}$ has been reported, with a significant equal success rate between patients with and without diverticula..$^{[5,8,27,31]}$

CBD stone clearance by basket or balloon was performed more frequently in Group B (94.9\%), as compared with $81.3 \%$ in Group A with a significant difference $(P<0.01)$, on contrary There was a trend of more frequent use of endoscopic mechanical lithotripsy in Group A (18.7\%) versus Group B (5.1\%) with significant difference $(P<0.001)$. Getsov et al., ${ }^{[28]}$ showed that there was a trend of more frequent use of endoscopic mechanical lithotripsy in patients with versus patients without PAD, but the difference did not reach statistical significance.

Association between PAD and ERCP-related complications is controversial. Our study showed that the presence of diverticula significantly increases the rate of perforation. Getsov et al., ${ }^{[28]}$ showed that the complication rate (acute pancreatitis, hemorrhage and acute cholangitis) was higher in patients with PAD than in patients without diverticula. Literature from single centers showed that the presence of diverticula significantly increases the rate of hemorrhage ${ }^{[33]}$ or hemorrhage and perforation..$^{[10,49,50]}$ On contrary, the majority of existing data indicates that no correlation between diverticula and an increased complication rate. ${ }^{[5,7,8,13,16,25,30-32,35,48]}$ A multicenter study showed an association of PAD with hemorrhage only in the univariate analysis, ${ }^{[51]}$ whereas another one found no association at all. ${ }^{[52]}$ The trend toward more complications in 
Group A is probably the result of the more difficult conditions at cannulation.

The association of PAD with recurrent choledocholithiasis after ES has been described, ${ }^{[7,22,24,25,30,38,53]}$ and this may be attributed to the previous reasons of primary stone formation. In our study, we have a significant recurrent biliary stone formation. However, our follow-up could be short to evaluate recurrence and have some limitations to rule out the residual stone. The mortality rate after ERCP was the same between patients with and without PAD.

Our study identified that three variables (abnormal papilla, $\mathrm{PAD}$, and stricture) were independently associated with difficult cannulation. On contrary, Panteris et al. ${ }^{\left[{ }^{[7]}\right.}$ identified that three variables (choledocholithiasis, abnormal papilla, and the presence of diverticula) were independently associated easier cannulation attempt.

\section{Conclusion}

The frequency of PAD was significantly higher in patients with the biliary stone disease than in patients with other co-morbid biliary diseases. The finding PAD has no effect on successful cannulation and early complication rate of ERCP but requires more skills in these patients. However, it is associated with increased attempts, difficult cannulation, decreased the rate of successful stone removal, prolonged procedure time and increased the incidence of primary and recurrent biliary stones formation. Therefore, more assessment of bile stone and its complications in these patients is persistently recommended.

\section{Financial support and sponsorship}

Nil.

\section{Conflicts of interest}

There are no conflicts of interest.

\section{References}

1. Chomel JB. The Royal Academy of History, Paris. Paris: The Institute France, Academy of Sciences; 1710. p. 37.

2. Morgagni GB. De sedibus, et causis morborum per anatomen indagatis libri quinque. Epist 34: Par 17. Naples; 1762.

3. Case JT. Diverticula of small intestine, other than Meckel's diverticulum. J Am Med Assoc 1920;75:1463-70.

4. Afridi SA, Fichtenbaum CJ, Taubin H. Review of duodenal diverticula. Am J Gastroenterol 1991;86:935-8.

5. Tyagi P, Sharma P, Sharma BC, Puri AS. Periampullary diverticula and technical success of endoscopic retrograde cholangiopancreatography. Surg Endosc 2009;23:1342-5.

6. Lobo DN, Balfour TW, Iftikhar SY, Rowlands BJ. Periampullary diverticula and pancreaticobiliary disease. Br J Surg 1999;86:588-97.

7. Panteris V, Vezakis A, Filippou G, Filippou D, Karamanolis D, Rizos S. Influence of juxtapapillary diverticula on the success or difficulty of cannulation and complication rate. Gastrointest Endosc 2008;68:903-10.

8. Tham TC, Kelly M. Association of periampullary duodenal diverticula with bile duct stones and with technical success of endoscopic retrograde cholangiopancreatography. Endoscopy 2004;36:1050-3.

9. Yildirgan MI, Basoglu M, Yilmaz I, Atamanalp SS, Balik AA, Aydinli B, et al. Periampullary diverticula causing pancreaticobiliary disease. Dig Dis Sci 2004;49:1943-5.

10. Boix J, Lorenzo-Zúñiga $\mathrm{V}$, Añaños $\mathrm{F}$, Domènech E, Morillas RM, Gassull MA. Impact of periampullary duodenal diverticula at endoscopic retrograde cholangiopancreatography: A proposed classification of periampullary duodenal diverticula. Surg Laparosc Endosc Percutan Tech 2006;16:208-11.

11. Sugiyama M, Atomi Y. Periampullary diverticula cause pancreatobiliary reflux. Scand J Gastroenterol 2001;36:994-7.

12. Katsinelos P, Dimiropoulos S, Pilpilidis I, Galanis I, Tsolkas P, Papagiannis A, et al. Endoscopic sphincterotomy in patients with "acalculus" cholangitis associated with juxtapapillary diverticula. Hepatogastroenterology 2004;51:649-51.

13. Mohammad Alizadeh AH, Afzali ES, Shahnazi A, Mousavi M, Doagoo SZ, Mirsattari D, et al. ERCP features and outcome in patients with periampullary duodenal diverticulum. ISRN Gastroenterol 2013;2013:217261.

14. American Society of Anesthesiologists. ASA Relative Value Guide 2002. Code 99140. Park Ridge, IL: ASA; 2002. p. xii.

15. Wang P, Li ZS, Liu F, Ren X, Lu NH, Fan ZN, et al. Risk factors for ERCP-related complications: A prospective multicenter study. Am J Gastroenterol 2009;104:31-40.

16. Katsinelos P, Chatzimavroudis G, Tziomalos K, Zavos C, Beltsis A, Lazaraki $\mathrm{G}$, et al. Impact of periampullary diverticula on the outcome and fluoroscopy time in endoscopic retrograde cholangiopancreatography. Hepatobiliary Pancreat Dis Int 2013;12:408-14.

17. Bailey AA, Bourke MJ, Kaffes AJ, Byth K, Lee EY, Williams SJ. Needle-knife sphincterotomy: Factors predicting its use and the relationship with post-ERCP pancreatitis (with video). Gastrointest Endosc 2010;71:266-71.

18. Vandervoort J, Soetikno RM, Tham TC, Wong RC, Ferrari AP Jr., Montes $\mathrm{H}$, et al. Risk factors for complications after performance of ERCP. Gastrointest Endosc 2002;56:652-6.

19. Ito K, Fujita N, Noda Y, Kobayashi G, Horaguchi J, Takasawa O, et al. Relationship between post-ERCP pancreatitis and the change of serum amylase level after the procedure. World J Gastroenterol 2007;13:3855-60.

20. Cotton PB, Lehman G, Vennes J, Geenen JE, Russell RC, Meyers WC, et al. Endoscopic sphincterotomy complications and their management: An attempt at consensus. Gastrointest Endosc 1991;37:383-93.

21. Isayama $\mathrm{H}$, Komatsu $\mathrm{Y}$, Tsujino $\mathrm{T}$, Sasahira N, Hirano K, Toda N, et al. A prospective randomised study of "covered" versus "uncovered" diamond stents for the management of distal malignant biliary obstruction. Gut 2004;53:729-34.

22. Kim DI, Kim MH, Lee SK, Seo DW, Choi WB, Lee SS, et al. Risk factors for recurrence of primary bile duct stones after endoscopic biliary sphincterotomy. Gastrointest Endosc 2001;54:42-8.

23. Lane JE, Ajjan M, Sedghi S. GI bleeding from duodenal diverticula. Am J Gastroenterol 2001;96:2799-800.

24. Ko KS, Kim SH, Kim HC, Kim IH, Lee SO. Juxtapapillary duodenal diverticula risk development and recurrence of biliary stone. J Korean Med Sci 2012;27:772-6.

25. Geraci G, Modica G, Sciumè C, Sciuto A. Intradiverticular ampulla of vater: Personal experience at ERCP. Diagn Ther Endosc 2013;2013:102571.

26. Løtveit T, Skar V, Osnes M. Juxtapapillary duodenal diverticula. Endoscopy 1988;20 Suppl 1:175-8.

27. Aslan F, Arabul M, Alper E, Celik M, Kandemir A, Unsal B. The impact of periampullary diverticula on the endoscopic treatment of choledocholithiasis. Prz Gastroenterol 2012;7:281-5.

28. Getsov P, Dineva S, Vladimirov B. Endoscopic retrograde cholangiopancreatography in patients with periampullary diverticula: Analysis of 3259 cases. J Med Sci Public Health 2014;3:35-42.

29. Boender J, Nix GA, de Ridder MA, van Blankenstein M, Schütte HE, Dees J, et al. Endoscopic papillotomy for common bile duct stones: Factors influencing the complication rate. Endoscopy 1994;26:209-16. 
30. Rajnakova A, Goh PM, Ngoi SS, Lim SG. ERCP in patients with periampullary diverticulum. Hepatogastroenterology 2003;50:625-8.

31. Vaira D, Dowsett JF, Hatfield AR, Cairns SR, Polydorou AA, Cotton PB, et al. Is duodenal diverticulum a risk factor for sphincterotomy? Gut 1989;30:939-42.

32. Lobo DN, Balfour TW, Iftikhar SY. Periampullary diverticula: Consequences of failed ERCP. Ann R Coll Surg Engl 1998;80:326-31.

33. Zoepf T, Zoepf DS, Arnold JC, Benz C, Riemann JF. The relationship between juxtapapillary duodenal diverticula and disorders of the biliopancreatic system: Analysis of 350 patients. Gastrointest Endosc 2001;54:56-61.

34. Viceconte G, Viceconte GW, Bogliolo G. Endoscopic manometry of the sphincter of Oddi in patients with and without juxtapapillary duodenal diverticula. Scand J Gastroenterol 1984;19:329-33.

35. Shemesh E, Klein E, Czerniak A, Coret A, Bat L. Endoscopic sphincterotomy in patients with gallbladder in situ: The influence of periampullary duodenal diverticula. Surgery 1990;107:163-6.

36. Chandy G, Hart WJ, Roberts-Thomson IC. An analysis of the relationship between bile duct stones and periampullary duodenal diverticula. J Gastroenterol Hepatol 1997;12:29-33.

37. Christoforidis E, Goulimaris I, Kanellos I, Tsalis K, Dadoukis I. The role of juxtapapillary duodenal diverticula in biliary stone disease. Gastrointest Endosc 2002;55:543-7.

38. Li X, Zhu K, Zhang L, Meng W, Zhou W, Zhu X, et al. Periampullary diverticulum may be an important factor for the occurrence and recurrence of bile duct stones. World J Surg 2012;36:2666-9.

39. Kennedy RH, Thompson MH. Are duodenal diverticula associated with choledocholithiasis? Gut 1988;29:1003-6.

40. Wu SD, Su Y, Fan Y, Zhang ZH, Wang HL, Kong J, et al. Relationship between intraduodenal peri-ampullary diverticulum and biliary disease in 178 patients undergoing ERCP. Hepatobiliary Pancreat Dis Int 2007;6:299-302.

41. Hagège H, Berson A, Pelletier G, Fritsch J, Choury A, Liguory C, et al. Association of juxtapapillary diverticula with choledocholithiasis but not with cholecystolithiasis. Endoscopy 1992;24:248-51.

42. van Nieuwkoop C, Boere I, Rosekrans PA, Bac DJ. Recurrent bacterial cholangitis due to a juxtapapillary diverticulum. Eur J Gastroenterol Hepatol 2002;14:189-90.

43. Shinagawa N, Fukui T, Mashita K, Kitano Y, Yura J. The relationship between juxtapapillary duodenal diverticula and the presence of bacteria in the bile. Jpn J Surg 1991;21:284-91.

44. Miyazaki S, Sakamoto T, Miyata M, Yamasaki Y, Yamasaki H, Kuwata K. Function of the sphincter of Oddi in patients with juxtapapillary duodenal diverticula: Evaluation by intraoperative biliary manometry under a duodenal pressure load. World J Surg 1995;19:307-12.

45. Sherman S, Hawes RH, Lehman GA. A new approach to performing endoscopic sphincterotomy in the setting of a juxtapapillary duodenal diverticulum. Gastrointest Endosc 1991;37:353-5.

46. van Basten JP, Stockbrügger R. Relationship between duodenal diverticuli, gallstones and duodenal and pancreaticobiliary disorders. Ned Tijdschr Geneeskd 1996;140:1122-5.

47. Ozogul B, Ozturk G, Kisaoglu A, Aydinli B, Yildirgan M, Atamanalp SS. The clinical importance of different localizations of the papilla associated with juxtapapillary duodenal diverticula. Can J Surg 2014;57:337-41.

48. Chang-Chien CS. Do juxtapapillary diverticula of the duodenum interfere with cannulation at endoscopic retrograde cholangiopancreatography? A prospective study. Gastrointest Endosc 1987;33:298-300.

49. Shemesh E, Klein E, Czerniak A, Coret A, Bat L. Endoscopic sphincterotomy in patients with gallbladder in situ: The influence of periampullary duodenal diverticula. Surgery 1990;107:163-6.

50. Chapman RW. Complications of ERCP. In: Green J, editor. Guidelines on Complications of Gastrointestinal Endoscopy. London: British Society of Gastroenterology; 2006. p. 20-5.

51. Freeman ML, Nelson DB, Sherman S, Haber GB, Herman ME, Dorsher PJ, et al. Complications of endoscopic biliary sphincterotomy. N Engl J Med 1996;335:909-18.

52. Loperfido S, Angelini G, Benedetti G, Chilovi F, Costan F, De Berardinis F, et al. Major early complications from diagnostic and therapeutic ERCP: A prospective multicenter study. Gastrointest Endosc 1998;48:1-10.

53. Cheon YK, Lehman GA. Identification of risk factors for stone recurrence after endoscopic treatment of bile duct stones. Eur J Gastroenterol Hepatol 2006;18:461-4. 